\title{
The benefit of directly comparing autism and schizophrenia for revealing mechanisms of social cognitive impairment
}

\author{
Noah J. Sasson • Amy E. Pinkham • \\ Kimberly L. H. Carpenter • Aysenil Belger
}

Received: 6 October 2010 / Accepted: 26 November 2010/Published online: 16 December 2010

(C) Springer Science+Business Media, LLC 2010

\begin{abstract}
Autism and schizophrenia share a history of diagnostic conflation that was not definitively resolved until the publication of the DSM-III in 1980. Though now recognized as heterogeneous disorders with distinct developmental trajectories and dissociative features, much of the early nosological confusion stemmed from apparent overlap in certain areas of social dysfunction. In more recent years, separate but substantial literatures have accumulated for autism and schizophrenia demonstrating that abnormalities in social cognition directly contribute to the characteristic social deficits of both disorders. The current paper argues that direct comparison of social cognitive impairment can highlight shared and divergent mechanisms underlying pathways to social dysfunction, a process that can provide significant clinical benefit by informing the development of tailored treatment efforts. Thus, while the history of diagnostic conflation between autism and schizophrenia may have originated in similarities in social dysfunction, the goal of direct comparisons is not to conflate them once again but rather to reveal distinctions that illuminate disorder-specific
\end{abstract}

\section{N. J. Sasson $(\bowtie)$}

School of Behavioral and Brain Sciences,

University of Texas at Dallas,

GR41, 800 W. Campbell Rd,

Richardson, TX 75080, USA

e-mail: nsasson@utdallas.edu

\section{A. E. Pinkham}

Department of Psychology, Southern Methodist University, Dallas, TX, USA

\section{K. L. H. Carpenter · A. Belger}

Department of Psychiatry, University of North Carolina, Chapel Hill, NC, USA

K. L. H. Carpenter

Curriculum in Neurobiology, University of North Carolina,

Chapel Hill, NC, USA mechanisms and pathways that contribute to social cognitive impairment.

Keywords Social cognition · Face processing - Emotion . Amygdala $\cdot$ Superior temporal sulcus $\cdot$ Fusiform gyrus

In his seminal 1943 paper "Autistic Disturbances of Affective Contact", Leo Kanner described a group of 11 children who shared a constellation of behavioral and affective symptoms, most notably "a powerful desire for aloneness and sameness" (Kanner 1943). A year later, the Austrian pediatrician Hans Asperger independently characterized several children he deemed "little professors" who exhibited "a lack of empathy, little ability to form friendships, one-sided conversations [and] intense absorption in a special interest" (Asperger 1944/1991). Both Kanner and Asperger, without apparent knowledge of each other's work, selected the term "autism" (from the Greek autos meaning "self") to capture the characteristic egocentrism in the children they were observing. The simultaneous choice of label, however, was not mere coincidence: "autism" had a long history in the psychiatric literature, dating back to 1911 when Eugen Bleuler used the word to describe social withdrawal in patients with schizophrenia:

Schizophrenics, who have no more contact with the outside world, live in a world of their own. They have encased themselves with their desires and wishes...; they have cut themselves off as much as possible from any contact with the external world. This detachment from reality, together with the relative and absolute predominance of the inner life, we term autism (Bleuler 1911).

Both Kanner and Asperger thus grounded their clinical descriptions of autism within the context of established 
psychiatric nomenclature. Each was keenly aware of Bleuler's use of the term and deliberately selected an accepted psychiatric label that connoted social disconnection. Although the application of such a recognized term had the intended result of facilitating understanding of the affective impairments they were describing, its close association with schizophrenia inadvertently resulted in considerable nosological confusion. Kanner and Asperger each appeared to struggle with this tradeoff. While Kanner maintained that autism was a distinct clinical syndrome from schizophrenia, separated by its apparent presence from birth, its peculiarities in repetitive interaction with objects, and its characteristic insistence on familiarity and routine, he believed the term "autism" was warranted because of a shared presentation of social isolation:

Nevertheless, in full recognition of [the differences], I was unable to find a concise expression that would be equally or more suitably applicable. After all, these children do start out in a state which, in a way, resembles the end results of later-life withdrawal, and there is a remoteness at least from the human portion of the external world (Kanner 1973).

Similarly, Asperger argued that "autism" was an appropriate designation for the children he was studying given their similarities with certain negative symptoms of schizophrenia:

I have chosen the label autism in an effort to define the basic disorder that generates the abnormal personality structure of the children we are concerned with here. The name derives from the concept of autism in schizophrenia. Autism in this sense refers to a fundamental disturbance of contact that is manifest in an extreme form of schizophrenic patients (Asperger 1944/1991).

Like Kanner, however, Asperger argued that the syndrome he was observing was an independent condition. His basis for the distinction was that "autism" did not share positive symptoms of schizophrenia (e.g., delusions, hallucinations, etc.) and followed a different developmental course:

Schizophrenic patients often live in an imaginary world of wish fulfillment and ideas of persecution... However this type of thinking does not play a role in the children we are concerned with here... While the schizophrenic patient seems to show progressive loss of contact, the children we are discussing lack contact from the start (Asperger 1944/1991).

Although this acknowledgment of independent developmental trajectories and symptom differentiation foreshadows the criteria that would eventually support diagnostic segregation of the two disorders, the emphasis on a shared social profile with schizophrenia - coupled with a term so strongly connected with it - helped fuel a debate over the next several decades concerning the appropriate classification of autism. Was it, as Kanner and Asperger originally contended, categorically independent from schizophrenia, or simply a childhood subtype? For many years, Kanner himself oscillated on this question, highlighting both similarities and differences between the two conditions (Kanner 1965). This ambiguity extended to the first edition of the Diagnostic and Statistical Manual (DSM), which defined "Schizophrenic reaction, childhood type" in part by "psychotic reactions in children, manifesting primarily autism" (American Psychiatric Association 1952). Similarly, the second DSM stated that childhood schizophrenia "may be manifested by autistic, atypical and withdrawn behavior" (American Psychiatric Association 1968). Even the title of the preeminent outlet for academic scholarship on autism, the Journal of Autism and Childhood Schizophrenia, reflected the uncertain relationship between the two disorders; it was not until 1979 that its title was changed to its current name, the Journal of Autism and Developmental Disorders (Schopler et al. 1979). The resolution of the diagnostic confusion between autism and schizophrenia would prove critically important not only for issues relating to classification, but also to etiology, pathophysiology, and treatment.

By the early 1970 s, a consensus began to emerge that designated autism and childhood schizophrenia as categorically distinct conditions. Although the efforts of many researchers and clinicians contributed to this development, the work of two individuals proved to be especially influential. The first, Michael Rutter, highlighted several key variables that differentiated schizophrenia and autism, most notably that the disorders occur within different families (Rutter 1968, 1972). Later, large-scale studies supported genetic dissociabilty by failing to find evidence for increased rates of schizophrenia in individuals with autism above what would be expected in the general population (Rumsey et al. 1985; Volkmar and Cohen 1991), although more recent work has re-opened the question of genetic relationships between the two disorders (Crespi et al. 2010; Szatmari et al. 2007). Also, central for establishing autism and schizophrenia as independent conditions was the work of Israel Kolvin who recognized that the two disorders were characterized by different ages of onset and independent developmental trajectories (Kolvin 1971). While symptoms of autism are observable by 3 years of age and in many cases even earlier, the defining symptoms of schizophrenia typically do not manifest until late adolescence or early adulthood. Even in the rare cases of younger children with schizophrenia, there are clear distinctions in clinical presentation from those with autism: importantly, childhood schizophrenia but not autism involves the presence of psychotic symptoms such as 
delusions and hallucinations (Green et al. 1984). This distinction was made explicit in the first diagnostic criteria for autism (American Psychiatric Association 1980), which precluded a diagnosis of autism unless there is an "absence of delusions, hallucinations, loosening of associations, and incoherence as in Schizophrenia". Further supporting diagnostic differentiation were salient differences in the early developmental course of the disorders: children with schizophrenia do not appear to exhibit characteristics of autism during the first 3 years of life, and children with autism are not at increased risk for developing schizophrenia later in development. In short, children with schizophrenia more closely resemble adults with schizophrenia than children with autism.

This work of Rutter and Kolvin ultimately helped sway the debate, and via decades of direct comparison between autism and schizophrenia, acceptance of partition was finally achieved. Separation was finalized when autism was introduced as an independent condition in DSM-III. This separation has been maintained in subsequent editions of the DSM, with autism continuing to be acknowledged as a qualitatively distinct disorder.

\section{Social dysfunction and social cognition-the foundation for renewing comparisons}

Despite the protracted history of autism and schizophrenia, or perhaps because of it, comparative studies between the disorders diminished considerably after publication of DSM-III. The frequency of such studies may have slowed due to the apparent "solution" that was reached concerning the relationship between autism and schizophrenia, or perhaps a new hesitancy emerged for pursuing studies that might somehow link two disorders that had previously required so much time and effort to separate. As a result, sizeable independent literatures have accumulated over the past 30 years investigating impairments in social functioning in both disorders. These studies have largely occurred in parallel and typically without comparison, despite notable overlap between the two disorders in this domain. Direct comparison, however, may still yield substantial benefit. As Kanner himself stated over 60 years ago, "The extreme isolation from other people, which is the foremost characteristic of early infantile autism, bears so close a resemblance to schizophrenic withdrawal that the relationship between the two conditions deserves serious consideration" (Kanner 1949).

This "close resemblance" in social dysfunction remains evident in current clinical characterizations of autism and schizophrenia. Both continue to be defined in part by pervasive social impairment that impairs the ability to initiate and maintain reciprocal interaction (American Psychiatric Association 1994). Individuals with autism frequently have flat affect in face and speech, impoverished language, reduced use of gesturing, concrete thinking, poor eye contact, obsessionality, and unusual body movements, all of which can be interpreted as symptoms of psychosis or schizophrenia (Volkmar and Cohen 1991; Dykens et al. 1991; Wing 1986). In this context, the initial confusion in clinical classification becomes easier to understand, and examination of current diagnostic criteria highlights areas of symptomatic overlap that can result in misdiagnosing those with autism as having schizophrenia (Howlin 2005) as well as symptom-negative patients with schizophrenia, as having autism (Sheitman et al. 2004).

A primary focus of both autism and schizophrenia research has been the specification of underlying neural and neuropsychological characteristics that may contribute to abnormalities in social dysfunction. One area that has effectively intersected these disparate domains is social cognition, a term that refers to the cognitive aspects of social experience, including the perception, processing and interpretation of social information (Brothers 1990). Social cognitive abilities range from the basic detection of biological motion and the recognition of facial affect to much more sophisticated "mentalizing" skills such as theory of mind and attribution formation. In both schizophrenia and autism, research attention turned to social cognition after general cognitive abilities were demonstrated to have limited utility in explaining or improving social dysfunction (Ben Itzchak et al. 2008; Penn et al. 1998). Indeed social impairment in schizophrenia has appeared to be especially resistant to treatment, and typically persists even when psychotic symptoms are effectively managed (Addington et al. 2003).

In recent years, the focus on social cognition has been validated by several studies demonstrating that social cognitive ability directly contributes to social functioning in both disorders (Couture et al. 2006; Klin et al. 2002; Pinkham et al. 2003; Hughes et al. 1997), even above and beyond general cognitive factors (Addington et al. 2010; Fett et al. 2010; Pinkham and Penn 2006). As such, social cognition may offer a profitable entry point for understanding the basis of social dysfunction and specify a potential target for remediation.

The emergence of social cognition as a viable research target has birthed large parallel literatures specific to each disorder, and much like the literature addressing social dysfunction, similarities are also markedly apparent in social cognition. In what follows, we present a brief review of social cognition in autism and schizophrenia highlighting areas of overlap that we believe provides a compelling argument for the potential benefits of direct comparison between the two disorders. Despite the fact that comparative designs have largely fallen out of favor, they offer particular promise for revealing shared and divergent 
mechanisms underlying pathways to social dysfunction, a process that not only holds immediate implications for identification, classification and etiology, but also for informing and refining the development of disorderspecific treatment efforts. Examining commonalities may also provide insight into deficit-specific, rather than disorder-specific, processes. In particular, overlapping features of social cognitive dysfunction suggest that autism and schizophrenia may share neurobiological substrates, particularly in systems relating to mechanisms of social functioning. At the same time, discovery of non-shared mechanisms may serve as an indication of equifinality, in which multiple pathways lead to similar end-points. In this case, social dysfunction may occur for very different reasons, and identification and understanding of divergent mechanisms that support social impairment across multiple disorders may aid the refinement of disorder-specific pathophysiology. Such independent mechanisms may well be expected to exist for autism and schizophrenia, given their unique developmental courses and non-shared characteristics.

\section{Social cognition in autism}

Social cognition is an area of marked dysfunction in autism that directly contributes to the disorder's pervasive social deficits (for review, see Pelphrey et al. 2004b). Studies of children and adults with autism have demonstrated extensive deficits in face processing (Klin et al. 1999; Langdell 1978; for review, see Sasson 2006) affect recognition (Baron-Cohen 1995; Baron-Cohen et al. 2001; Celani et al. 1999; Edwards et al. 2002; Loveland et al. 1997), gaze processing (Baron-Cohen et al. 1999a; Mundy et al. 1986), the detection of biological motion (Blake et al. 2003), and the visual scanning of faces (Pelphrey et al. 2002) dynamic social interactions (Klin et al. 2002) and emotionally charged scenes (Sasson et al. 2007). Investigations of the neural correlates of these deficits have reliably implicated a network of brain structures that include the fusiform gyrus (FG), the superior temporal sulcus (STS), the medial prefrontal cortex (MPFC), and the amygdala (AMY) (Pinkham et al. 2003; Pelphrey et al. 2004a) (see Fig. 1).

The FG, STS, and MPFC are activated in face recognition (Kanwisher et al. 1997), biological motion (Haxby et al. 2000), and theory of mind (Castelli et al. 2000), respectively, and each has been demonstrated to be structurally and/or functionally abnormal in autism (Castelli et al. 2000, 2002; Baron-Cohen et al. 1994; Schultz et al. 2000). The AMY, which has long served as a primary target of social cognitive researchers for its extensive contribution to social perception and cognition (Adolphs et al. 1995, 1998; LeDoux 1996), has also been reported to be abnormal in autism, both structurally (Brambilla et al.

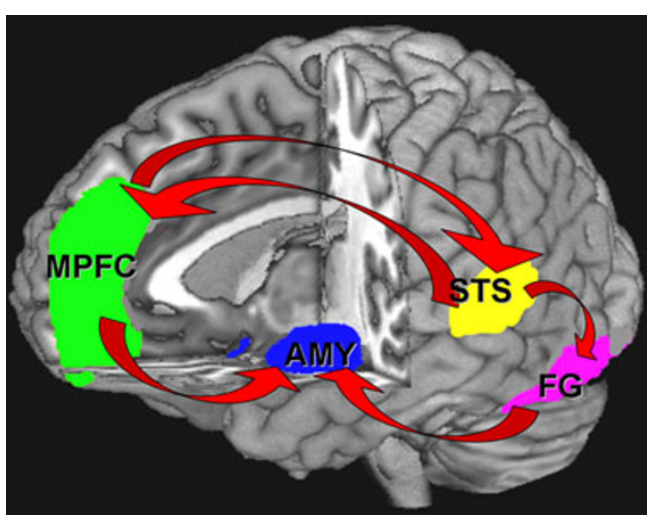

Fig. 1 Neural circuitry of social cognition

2003; Nacewicz et al. 2006) and functionally (Baron-Cohen et al. 1999b; Critchley et al. 2000), and is presumed to underlie the deficits in social appraisal and recognition of negative affect found in the disorder (Adolphs et al. 2001; Capps et al. 1992). The role of the AMY as a contributing factor to the social deficits in autism is supported by the similarity that individuals with autism have to both individuals with AMY damage, and to monkeys that have had ablations to their AMY early in life. For example, individuals with autism have been reported to have stronger reactions to typically non-threatening situations and decreased reactions in instances where typically developing individuals would usually exhibit fear (Bachevalier and Loveland 2006). Additionally, they have difficulties regulating their affective responses to both social and non-social stimuli, and they perform similarly to individuals with bilateral AMY lesions on tests of social trustworthiness and approachability, as well as when identifying the emotional features in facial expressions (Pelphrey et al. 2002; Adolphs et al. 2001, 2002; Graham et al. 2007). Structural analysis of the AMY in autism has also suggested that the developmental trajectory of the AMY is altered in individuals with autism. Namely, the AMY appears to be larger in children and young individuals with autism (Hrdlicka et al. 2005; Sparks et al. 2002). This has been hypothesized to be associated with a decrease in the pruning within the AMY of individuals with autism (Howard et al. 2000). Studies of adults with autism, however, have reported reduced (Aylward et al. 1999; Pierce et al. 2001; Rojas et al. 2004) or normal AMY size (Palmen et al. 2006; Schumann et al. 2004) suggesting that the overgrowth is restricted to early development and is followed by a period of either halted growth, or potentially increased neural pruning (Aylward et al. 1999; Schumann et al. 2004).

Several fMRI studies have further suggested that the AMY may be dysregulated in individuals with autism, though there is controversy as to the direction of this dysregulation. The majority of studies have found hypoactivation in the AMY in response to emotional faces, though this finding has not always been replicated 
(Baron-Cohen et al. 1999b; Critchley et al. 2000; Pelphrey et al. 2007; Ashwin et al. 2007; Hall et al. 2010). For example, Dalton et al. (2005) reported a strong positive correlation between the time that individuals with autism spend fixating on eyes and the activation elicited in both their AMY and FG. New research suggests that some of the discrepancy in the functional AMY findings may be attributed to altered habituation of the AMY to social stimuli. When measures of change over time in activation of AMY and FG to neutral facial stimuli in adults with autism spectrum disorders and healthy comparison adults were compared, the comparison group evidenced significantly greater AMY habituation bilaterally than the autism spectrum group, and this was associated with more severe social impairments (Kleinhans et al. 2009). Together these findings suggest that the AMY plays an integral role in establishing and maintaining proper social cognitive responses to environmental cues and that AMY dysfunction likely contributes to the social deficits seen in autism.

In addition to the AMY, the FG has been a region of great interest in the social cognitive research of autism. Several studies have reported decreased activation in the FG to a variety of social tasks in individuals with autism (Schultz et al. 2000; Critchley et al. 2000; Pierce et al. 2001); however, this has not always been replicated in tasks of more basic face processing (Dalton et al. 2005; Hadjikhani et al. 2004, 2007) and the processing of familiar faces (Pierce et al. 2004). It has been suggested that the hypoactivation may be due to decreased attention to the face stimuli, as evidenced by scan path analysis (Dalton et al. 2005) rather than an association with a more basic deficit in FG function. Like the AMY, the FG has been found to have structural alterations, in addition to functional deficits, in individuals with autism. These structural alterations include decreased numbers of neurons in the FG and a smaller size of the neurons that are present as compared to typically developing individuals (van Kooten et al. 2008).

The role of the STS in the pathophysiology of autism has been demonstrated utilizing a number of paradigms. The STS is important for processing the changeable aspects of social stimuli (Haxby et al. 2000; Winston et al. 2004), and specifically, it is important for differentiating biological motion from non-biological motion (Pelphrey et al. 2003) and is involved in utilizing eye-gaze information to infer the mental states of others (Hoffman and Haxby 2000; Pelphrey et al. 2004b). Individuals with autism have been shown to have difficulties with both of these social processes, as noted above, and fMRI experiments suggest that such impairments are at least in part due to deficiencies in STS activation. For example, the STS of typically developing individuals has been shown to activate in response to stimuli that approximate biological motion, but not to stimuli that share all of the same perceptual qualities as the biological motion with the exception they approximate mechanical motion (Pelphrey et al. 2003). A review by Pelphrey and Carter (2008) notes that this differential effect may not be present in individuals with autism. Instead, the STS of individuals with autism may activate similarly to both biological and non-biological motion. Furthermore, the STS of typically developing individuals has been shown to activate to a greater extent in conditions where the eye-gaze information of another person is incongruent with respect to what is expected (e.g., if the other person looks away from a suddenly appearing stimulus), while the STS of individuals with autism does not appear to make this distinction (Pelphrey et al. 2005). In addition to the functional differences of STS activation, recent reports suggest that there are also structural differences in the STS of individuals with autism. Specifically, after controlling for both age and total brain volume, the right STS appears to be larger in individuals with autism as compared to typically developed controls (Jou et al. 2010).

Collectively, these findings indicate significant impairments in social cognitive functioning in autism both at the behavioral and neural level, though a gap remains in the autism literature for charting the structural and functional trajectory of these regions over the course of development. Because autism is a persistent neurodevelopmental disorder whose symptoms can begin to be observable by 12 months of age (Zwaigenbaum et al. 2005), the preponderance of autism research has focused either on young children or on adults, depending on testing demands and population access. A critical need remains, however, for assessing developmental changes in social cognitive impairment and to determine how early-emerging deficits in "building block" social cognitive skills such as joint attention and social orienting contribute to the construction of broader abnormalities in social cognition later in development.

Social cognition in schizophrenia

The centrality of social dysfunction in schizophrenia has prompted considerable study of factors that may contribute to these impairments. Accordingly, social cognition is increasingly recognized as a core domain of cognitive functioning in schizophrenia (Addington et al. 2010; Green et al. 2005; Harvey and Penn 2010). A substantial body of work has demonstrated that adults with schizophrenia are impaired across a number of social cognitive domains (Penn et al. 2006) including emotion perception (Edwards et al. 2002; Kohler et al. 2010; Pinkham et al. 2007a); for review, see Li et al. 2010, theory of mind (Bora et al. 2009; Sprong et al. 2007; Mier et al. 2010), the perception of social cues (Archer et al. 1994; Van't Wout et al. 2009), making complex social judgments (Baas et al. 2008; Haut 
and MacDonald 2010), visual scanning of faces (Loughland et al. 2002; Phillips and David 1998; Streit et al. 1997), and detecting biological motion (Kim et al. 2005). Additionally, individuals with schizophrenia show biases in attributional style, another domain of social cognition that refers to the way individuals explain the behaviors of others (Aakre et al. 2009; Bentall et al. 2001; Langdon et al. 2010).

Investigations of structural changes in critical nodes along the social cognition network, including the FG, STS, MPFC, and AMY, have been less consistent. While some studies have reported volumetric reductions in the FG (Lee et al. 2002) and AMY (Wright et al. 2000), others reported no significant group differences in AMY volume (Goghari et al. 2010) raising the question of the unique role of the AMY in social cognitive impairment in schizophrenia. Additionally, abnormal levels of activation have been noted in both the FG (Quintana et al. 2003) and AMY (Pinkham et al. 2007b) while viewing and evaluating faces although with inconsistent findings, ranging from reduced AMY response to fearful faces (Brunet-Gouet and Decety 2006; Pinkham et al. 2008a) to increased activity in medial temporal lobe structures, including the AMY (Kosaka et al. 2002; Holt et al. 2006; Russell et al. 2007; Gur et al. 2007). Such differences may be attributed to variations in experimental designs, drug status, antipsychotic dose, and genetic variability in the patient population. Recent evidence suggests that reduced limbic activity in schizophrenia in response to social emotional stimuli may not represent a core heritable trait aspect of the disorder, but rather may be associated with "state" characteristics, such as treatment and symptom severity (Rasetti et al. 2009). It is therefore possible that limbic, and specifically AMY activation deficits, may not be equally central to the pathophysiology of social cognition in autism and schizophrenia. Studying individuals at risk for the two disorders, such as unaffected siblings may provide critical clues into this possibility.

Alterations along other nodes in the fronto-limbic circuitry in response to social emotional stimuli are also reported in schizophrenia (see Fig. 1). For instance, reduced frontal cortex volumes (Convit et al. 2001; Crespo-Facorro et al. 2000) as well as reduced MPFC activation during theory of mind tasks (Brunet et al. 2003), are also evident in adults with schizophrenia. Notably, despite evidence of volumetric reductions in the superior temporal gyrus (Davatzikos et al. 2005), some studies suggest that STS functioning may be largely intact in schizophrenia. Both studies of theory of mind and social evaluations of faces have failed to find activation differences in the STS between individuals with schizophrenia and healthy adults (Pinkham et al. 2008a; Brunet et al. 2003) (although see (Mier et al. 2010) for a recent exception).

While behavioral and neural impairments in social cognition are firmly established in adults with schizophrenia, substantially less is known about how these impairments develop or to what degree they are evident in children and adolescents prior to illness onset. These gaps may in part be attributed to the relatively late onset of illness associated with schizophrenia; however, recent advances in identifying individuals at risk for the development of schizophrenia capitalize on the prodromal phase of illness and provide valuable opportunities for examining when and how social cognitive impairments emerge in adults. Such studies have identified both impairments in theory of mind (Marjoram et al. 2006; Yu Sun et al. 2008) and emotion recognition among individuals who are at risk (Addington et al. 2008a), though there is limited information regarding the potential neural underpinnings of these behavioral deficits. Structural MRI investigations support reductions in the AMY and AMY-hippocampal complex volumes in at-risk adolescents (Keshavan et al. 1997, 2002; Lawrie et al. 2003; Schreiber et al. 1999; Chan et al. 2009), and one study has reported abnormal activation of several brain regions related to social cognition including the FG (Seiferth et al. 2008). This initial evidence demonstrates that neural abnormalities precede formal illness onset and suggest that the emergence of social cognitive deficits in schizophrenia may follow a distinct developmental trajectory.

\section{Integrative studies}

As these summaries demonstrate, a qualitative comparison of both literatures indicates that autism and schizophrenia exhibit strikingly similar abnormalities at both the behavioral and neural levels across a wide range of social cognitive abilities. Drawing definitive conclusions across disorders from these studies is difficult, however, as the parallel nature of the work has resulted in the use of tremendously varied methodology and sample characteristics. Additionally, a range of experimental tasks has been used, many of which are novel and specific to a single study, and therefore lacking replication within the same clinical group, much less utilization with a comparison disorder. This lack of uniformed social cognitive measures inhibits the potential for reaching sound conclusions across the clinical groups. Furthermore, sample characteristics often differ widely across studies. Because autism is diagnosed in early childhood while the onset of schizophrenia typically does not occur until early adulthood, independent studies of social cognition in each of the two disorders often include groups of incomparable ages. Even in studies of adults with autism, level of functioning and general cognitive abilities can differ substantially from similar studies of adults with schizophrenia. These differences in sample composition have made comparisons across studies all the more complicated.

Well-designed and well-matched direct comparisons between autism and schizophrenia avoid these problems, 
and are better equipped to deconstruct shared and divergent patterns of social cognitive performance. The handful of behavioral studies that have embraced this approach indicate that the similarities between disorders may not be as comprehensive as the independent literatures would suggest. While several direct comparisons have highlighted similar impairments in certain capacities for autism and schizophrenia - theory of mind (Craig et al. 2004; Pilowsky et al. 2000), eye gaze on faces in social scenes (Sasson et al. 2007), and judgments of facial trustworthiness and the identification of emotion from impoverished "point-light motion displays" (Couture et al. 2010) —others have found differences, including greater impairment in autism than schizophrenia in facial affect recognition (Bolte and Poustka 2003; Van Lancker et al. 1989) and social orienting (Sasson et al. 2007). The single direct neural comparison of social cognitive functioning between autism and schizophrenia (Pinkham et al. 2008a) demonstrated comparable levels of hypoactivation in a network of regions implicated in social cognitive processing, including the FG, AMY, and ventrolateral prefrontal cortex in both disorders. These findings were interpreted as revealing a shared neural basis for social cognitive impairment; however, the sample sizes were small, and future direct neural comparisons are clearly needed to determine whether different disorders with similar behavioral characteristics truly show similarities in brain circuitry and brain functioning, or whether different neural profiles may underlie surface similarities.

\section{Shared social cognitive impairments-convergence and divergence}

What explains the seemingly shared social cognitive impairments between autism and schizophrenia? From one perspective, this overlap may indicate convergence across multiple domains. Convergence may suggest a shared genetic etiology in which there are genes that are associated with social cognitive deficits spanning both disorders. Indeed, recent work indicates a link between the Disrupted in Schizophrenia 1 (DISC1) gene and aspects of mental illness that co-occur in autism and schizophrenia (Marx J 2007). Additionally, common chromosomic regions have been implicated in each disorder (Di Cristo 2007; Vorstman et al. 2006) and a copy number variant disruption of the neurexin-1 gene (Szatmari et al. 2007; Friedman et al. 2006) has also been reported for both. Finally, both disorders have been associated with deficits in multiple genes important for proper neurodevelopment (for review, see Fatemi 2010).

Convergence in social cognitive deficits may also indicate a shared neural profile in autism and schizophrenia (Pinkham et al. 2008b) in which abnormal functioning of brain regions in the social cognitive neural network similarly affects both groups. Although Pinkham et al. (Pinkham et al. 2008a) remains the only direct comparison of activation in the social cognitive network between the two disorders, the fact that shared impairments in face processing, theory of mind and other social cognitive abilities are well mapped to specific neural regions, independently studied in each disorder, suggests that autism and schizophrenia may in fact share abnormalities in the "social brain" that account for the widely reported behavioral deficits in social cognition.

The etiology of these shared neural profiles, however, remains very much in question. A recent review of existing datasets characterizing autism and schizophrenia (Cheung et al. 2010) has suggested that despite significant overlap in neuroanatomy common to both autism and schizophrenia, there are also significant differences and unique features to each disorder. For instance, lower gray matter volume within limbic-striato-thalamic circuitry appears to be common to both disorders, whereas decreased gray matter volume in the AMY in adulthood appears to be a feature of schizophrenia. This contrasts with other studies that have emphasized the centrality of the AMY in autism (Baron-Cohen et al. 2000) as compared with the association of AMY volume reduction with illness progression in schizophrenia. This heterogeneity in neuroanatomical findings in autism and schizophrenia highlights the need to better understand the associated neurobiological pathways underlying the convergent social cognitive profiles that emerge in adulthood for each disorder.

Indeed, while reports of convergence undoubtedly serve a valuable need by helping target potential shared genetic and neural mechanisms, they may nevertheless occlude the discovery of disorder-specific mechanisms that may better inform etiology and pathophysiology. In this sense, convergence showcases provocative overlap between the two conditions, but cannot account for how or why this overlap occurs. As remarkable as the similarities often appear, they do not necessarily imply shared etiology or development of these impairments. Adults with autism and adults with schizophrenia might both exhibit abnormal social behaviors, and even perform similarly on many social cognitive tasks, yet clinically and interpersonally they often present very differently. What accounts for these differences? And how do we capture them? One approach is to seek out divergence in addition to convergence by highlighting specific aspects of social cognitive performance that may differ between the two disorders despite general similarities. In this sense, when assessing social cognitive performance in autism and schizophrenia, it is not enough to address the question of performance accuracy, but also the question of process, or how each group performs the task. While individuals in both clinical populations may perform similarly on a wide range of social cognitive tasks, the 
process by which they reach their conclusions, assessments and judgments may differ markedly between groups, and indeed, even between individuals. An approach emphasizing divergence, therefore, acknowledges the overlap in social cognitive impairment, but conceptualizes shared impairment as a developmental end-point that must be differentiated from developmental process. Thus, locating aspects of divergence may represent disorder-specific mechanisms that provide clues about the distinct pathways that can lead to shared social cognitive end-points.

As an example of such work, Sasson et al. (2007) reported that, relative to typically developing comparison participants, both adults with autism and adults with schizophrenia demonstrated reduced visual attention to faces while making emotional evaluations within complex social scenes. Such a finding, as others before it, identifies a shared abnormality between the two disorders in an aspect of social information processing, and as such, provides another example of convergence in social cognitive performance. However, this finding alone cannot determine whether similar or discrepant mechanisms contributed to the overlap in the two groups. By extending their findings to also examine the latency to fixate gaze to faces in the scenes, the authors found an important mechanistic discrepancy between the autism and schizophrenia groups: only the autism group failed to orient to faces normally. While both the schizophrenia group and typically developing comparison participants oriented to faces quicker when they included meaningful emotional information relative to when such information was digitally erased, the autism group oriented at the same rate across both conditions. Thus, only the autism group failed to modulate their orienting mechanism based upon the presence of discernable facial affect and, while both groups shared an abnormality in utilizing facial information for assessing emotional content within the scenes, they differed in the ability to seek out emotionally relevant cues within these complex social stimuli. This impairment in social orienting, specific to the autism group, is consistent with developmental studies indicating that individuals with autism demonstrate impaired orienting to social stimuli from very early in life (Baranek 1999; Dawson et al. 2004; Osterling et al. 2002) and as such, highlights a potential mechanism that may constitute a fundamental and persistent characteristic unique to autism that is not shared with schizophrenia.

It is reasonable to assume that there may be other divergent mechanisms of social cognitive impairment between autism and schizophrenia. Although both share deficits in a range of social cognitive abilities, a number of reasons suggest that mechanisms supporting these impairments may differ. Firstly, the markedly different ages of onset suggest that separate developmental pathways may underlie the emergence of social cognitive impairment in autism and schizophrenia. A recent work from our group supports this notion by finding evidence suggesting normative levels of experience with faces during childhood and adolescence in schizophrenia (Pinkham et al. 2008b) with social cognitive impairments emerging most prominently after the first psychotic episode in early adulthood (Pinkham et al. 2007a). In contrast, from early childhood individuals with autism demonstrate profound impairments in face perception that persist throughout the lifespan (Sasson 2006).

Secondly, the handful of studies that have directly compared social cognition in autism and schizophrenia (Sasson et al. 2007; Craig et al. 2004; Pilowsky et al. 2000; Bolte and Poustka 2003) suggest an intriguing pattern in which individuals with schizophrenia may outperform individuals with autism on tasks of basic social perception (e.g., emotion identification and social orienting) but perform similarly to individuals with autism on tasks that require higher levels of social cognitive skill (e.g., inferring intent and belief). Although speculative, this raises the interesting possibility that the two disorders may differ in the earliest point of social cognitive disruption; while autism may be characterized by primary impairments in social perceptual mechanisms that lead to social cognitive dysfunction, schizophrenia may retain intact social perception but show abnormalities in higher order social cognitive processes. Alternatively, one disorder may be characterized by an early disruption in the functioning of a specific node, whereas social cognitive dysfunction in the other disorder may be a result of a loss of connectivity and top down regulation of early social affective perception, as depicted in the theoretical model in Fig. 2. Additionally, the direct comparison of other domains in autism and schizophrenia suggest divergent profiles in general cognition (Bolte et al. 2002) and perception (Bolte et al. 2007), each of which could potentially contribute to important mechanistic dissociations in social information processing. Future research that examines how differences in these broader domains impact social cognitive abilities in the two disorders is warranted.

Finally, preliminary evidence suggests that autism and schizophrenia may differ in strategies for evaluating social and emotional content. Individuals with schizophrenia may be more likely to misinterpret social cues by "jumping to conclusions" in their appraisal of emotional information (Freeman 2007), while individuals with autism may exhibit difficulty decoding emotional information due to perceptual integration impairments that hinder the interpretation of complex social information (Happe and Frith 2006). Both strategies may result in poor performance on social cognitive tasks, though the underlying mechanisms may differ. One compelling new theory suggests that autism and schizophrenia may represent diametric genetic conditions 
Fig. 2 Theoretical models of the neurobiological underpinnings of social cognitive dysfunction in schizophrenia and autism

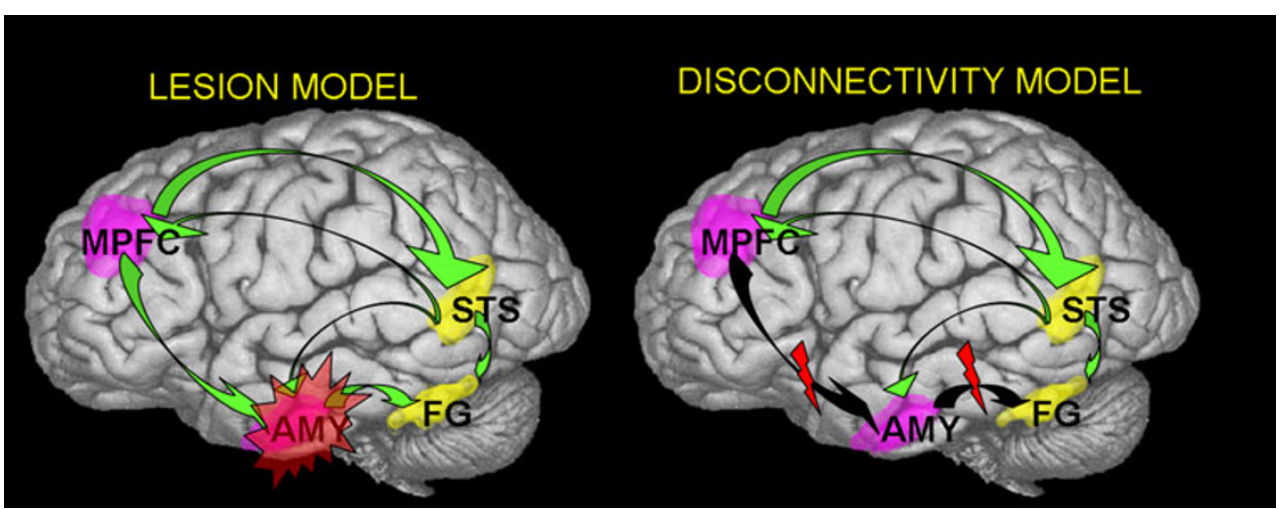

that manifest in more "under-developed" social abilities in autism (e.g., language, theory of mind) and a more "overdeveloped" social phenotype in schizophrenia (e.g., paranoia) (Crespi et al. 2010; Crespi and Badcock 2008). From this perspective, the social impairments in autism and schizophrenia may be conceptualized by a differentiation of greater hyposociality in autism and hypersociality in schizophrenia (at least in its paranoid variant). Evidence for this segmentation is supported by studies demonstrating exaggerated theory of mind biases in schizophrenia that result in the over- and misattribution of intentionality (Abu-Akel and Bailey 2000; Frith 2004; Montag et al. 2010; Walter et al. 2009), while studies of theory of mind impairments in autism relate more to the under attribution of mental states (Baron-Cohen 1995; Happe 1994). Future comparative research that further explores and refines this distinction may prove valuable.

\section{Challenges and conclusions}

While the direct comparison of autism and schizophrenia offers the potential to expose independent mechanisms contributing to social cognitive dysfunction, the process of implementing such studies presents significant challenges. Recruitment and assessment across multiple clinical populations can be difficult, especially for researchers who may be more familiar with, and have greater access to, only one of the two disorders. Collaboration among researchers who share expertise and resources can help mitigate this problem. An additional challenge occurs in selecting appropriate age groups to compare, especially given the vastly different developmental courses of autism and schizophrenia. While much of the social cognition work in autism has occurred with children of various ages, the preponderance of studies in schizophrenia has occurred with adults. Limiting comparisons to matched samples of adults with autism and adults schizophrenia avoids this confound but may introduce others, as the two groups may differ in medication usage and/or treatment history.
Designs that examine neurophysiological mechanisms that are less affected by medication and treatment may therefore be preferred to those that are more directly impacted.

Comparative studies also need not be limited to adults. Investigations of younger individuals may eliminate some of the confounds posed by adult studies, and also present an opportunity to examine the emergence of impairments during a period of rapid change in brain and behavior. A substantial literature has developed indicating that social impairments in individuals with schizophrenia predate formal diagnosis, not only during the prodromal phase in adolescence (Addington et al. 2008b; Ballon et al. 2007; Cannon et al. 2008) but also during early childhood (Asarnow 1988; Isohanni et al. 2000; Jones 1997; Jones and Tarrant 2000; Mirsky et al. 1995). These studies highlight the protracted developmental course of schizophrenia and demonstrate that social deficits are not simply a byproduct of symptoms that occur with formal onset of the illness (e.g., anhedonia), but rather an early-emerging, defining, and persistent characteristic of the disorder. Moreover, early identification of individuals at risk for schizophrenia is improving (Cannon et al. 2007) and thus offers increased potential for the study of social cognitive abilities prior to the formal onset of illness. Work focusing on children and adolescents at high risk for psychosis therefore provides a basis for pursuing developmentally based comparative studies with autism and offers promise for charting the multiple trajectories leading to the overlapping social cognitive deficits found in adulthood.

Identifying dissociable mechanisms may help deconstruct the complex processes underlying social cognitive impairments and facilitate the identification of disorder-specific pathways and mechanisms. Furthermore, linking these mechanisms to developmental processes during critical periods of brain development could help refine our understanding of the specific brain-behavior transactions subserving emergent abnormalities in social dysfunction. The search for divergent mechanisms underlying social cognitive impairment in autism and schizophrenia becomes particularly relevant for the development of efficacious treatment and intervention 
programs. By emphasizing convergence in our treatment approaches rather than divergence, we run the risk of treating superficial similarities rather than root causes. As Kanner stated while referring to autism and schizophrenia (here identified as "the schizophrenia bundle"): "When we stop searching for an identical cause and treatment of different ailments tied together in the schizophrenia bundle, we may expect the opening up of new and clearer vistas" (Kanner 1965).

\section{References}

Aakre JM, Seghers JP, St-Hilaire A, Docherty N. Attributional style in delusional patients: a comparison of remitted paranoid, remitted nonparanoid, and current paranoid patients with nonpsychiatric controls. Schizophr Bull. 2009;35(5):994-1002.

Abu-Akel A, Bailey AL. The possibility of different forms of theory of mind impairment in psychiatric and developmental disorders. Psychol Med. 2000;30(3):735-8.

Addington J, Young J, Addington D. Social outcome in early psychosis. Psychol Med. 2003;33(6):1119-24.

Addington J, Penn D, Woods SW, Addington D, Perkins DO. Facial affect recognition in individuals at clinical high risk for psychosis. Br J Psychiatry. 2008a;192(1):67-8.

Addington J, Penn D, Woods SW, Addington D, Perkins DO. Social functioning in individuals at clinical high risk for psychosis. Schizophr Res. 2008b;99(1-3):119-24.

Addington J, Girard TA, Christensen BK, Addington D. Social cognition mediates illness-related and cognitive influences on social function in patients with schizophrenia-spectrum disorders. J Psychiatry Neurosci. 2010;35(1):49-54.

Adolphs R, Tranel D, Damasio H, Damasio AR. Fear and the human amygdala. J Neurosci. 1995;15(9):5879-91.

Adolphs R, Tranel D, Damasio AR. The human amygdala in social judgment. Nature. 1998;393(6684):470-4.

Adolphs R, Sears L, Piven J. Abnormal processing of social information from faces in autism. J Cogn Neurosci. 2001;13(2):232-40.

Adolphs R, Baron-Cohen S, Tranel D. Impaired recognition of social emotions following amygdala damage. J Cogn Neurosci. 2002;14 (8):1264-74.

American Psychiatric Association. Diagnostic and Statistical Manual of Mental Disorders: DSM-I. 4th ed. Washington, DC: American Psychiatric Association; 1952.

American Psychiatric Association. Diagnostic and Statistical Manual of Mental Disorders: DSM-II. 4th ed. Washington, DC: American Psychiatric Association; 1968.

American Psychiatric Association. Diagnostic and Statistical Manual of Mental Disorders: DSM-III. 4th ed. Washington, DC: American Psychiatric Association; 1980.

American Psychiatric Association. Diagnostic and Statistical Manual of Mental Disorders: DSM-IV. 4th ed. Washington, DC: American Psychiatric Association; 1994.

Archer J, Hay DC, Young AW. Movement, face processing and schizophrenia: evidence of a differential deficit in expression analysis. Br J Clin Psychol. 1994;33(Pt 4):517-28.

Asarnow JR. Children at risk for schizophrenia: converging lines of evidence. Schizophr Bull. 1988;14(4):613-31.

Ashwin C, Baron-Cohen S, Wheelwright S, O'Riordan M, Bullmore ET. Differential activation of the amygdala and the 'social brain' during fearful face-processing in Asperger Syndrome. Neuropsychologia. 2007;45(1):2-14.
Asperger H. Die Sutistichen Psychopathen: im Kindersalter. Archive Fur Psychiatrie und Nervenkrankheiten. 1944/ 1991;117:76-136. (Reprinted in Autism and Asperger Syndrome by U. Frith, Ed., 1991. Cambridge, UK: Cambridge University Press).

Aylward EH, Minshew NJ, Goldstein G, Honeycutt NA, Augustine $\mathrm{AM}$, Yates $\mathrm{KO}$, et al. MRI volumes of amygdala and hippocampus in non-mentally retarded autistic adolescents and adults. Neurology. 1999;53(9):2145-50.

Baas D, van't Wout M, Aleman A, Kahn RS. Social judgement in clinically stable patients with schizophrenia and healthy relatives: behavioural evidence of social brain dysfunction. Psychol Med. 2008:38(5):747-54.

Bachevalier J, Loveland KA. The orbitofrontal-amygdala circuit and self-regulation of social-emotional behavior in autism. Neurosci Biobehav Rev. 2006;30(1):97-117.

Ballon JS, Kaur T, Marks II, Cadenhead KS. Social functioning in young people at risk for schizophrenia. Psychiatry Res. 2007;151(1-2):29-35.

Baranek GT. Autism during infancy: a retrospective video analysis of sensory-motor and social behaviors at 9-12 months of age. J Autism Dev Disord. 1999;29(3):213-24.

Baron-Cohen S. Mindblindness. Boston: MIT Press/Bradford Books; 1995.

Baron-Cohen S, Ring H, Moriarty J, Schmitz B, Costa D, Ell P. Recognition of mental state terms. Clinical findings in children with autism and a functional neuroimaging study of normal adults. Br J Psychiatry. 1994;165(5):640-9.

Baron-Cohen S, Campbell R, Karmiloff-Smith A, Grant J, Walker J. Are children with autism blind to the mentalistic significance of the eyes? Br J Dev Psychol. 1999a;13:379-98.

Baron-Cohen S, Ring HA, Wheelwright S, Bullmore ET, Brammer MJ, Simmons A, et al. Social intelligence in the normal and autistic brain: an fMRI study. Eur J Neurosci. 1999b;11 (6):1891-8.

Baron-Cohen S, Ring HA, Bullmore ET, Wheelwright S, Ashwin C, Williams SC. The amygdala theory of autism. Neurosci Biobehav Rev. 2000;24(3):355-64.

Baron-Cohen S, Wheelwright S, Hill J, Raste Y, Plumb I. The "Reading the Mind in the Eyes" Test revised version: a study with normal adults, and adults with Asperger syndrome or highfunctioning autism. J child psychol psychiatry allied discipl. 2001;42(2):241-51

Ben Itzchak E, Lahat E, Burgin R, Zachor AD. Cognitive, behavior and intervention outcome in young children with autism. Res Dev Disabil. 2008;29(5):447-58.

Bentall RP, Corcoran R, Howard R, Blackwood N, Kinderman P. Persecutory delusions: a review and theoretical integration. Clin Psychol Rev. 2001;21(8):1143-92.

Blake R, Turner LM, Smoski MJ, Pozdol SL, Stone WL. Visual recognition of biological motion is impaired in children with autism. Psychol Sci. 2003;14(2):151-7.

Bleuler E. Dementia Praecox or the Group of Schizophrenias: trans. E. Zinkin. New York: International Universities Press; 1911/1951.

Bolte S, Poustka F. The recognition of facial affect in autistic and schizophrenic subjects and their first-degree relatives. Psychol Med. 2003;33(5):907-15.

Bolte S, Rudolf L, Poustka F. The cognitive structure of higher functioning autism and schizophrenia: a comparative study. Compr Psychiatry. 2002;43(4):325-30.

Bolte S, Holtmann M, Poustka F, Scheurich A, Schmidt L. Gestalt perception and local-global processing in high-functioning autism. J Autism Dev Disord. 2007;37(8):1493-504.

Bora E, Yucel M, Pantelis C. Theory of mind impairment in schizophrenia: meta-analysis. Schizophr Res. 2009;109(1-3):1-9.

Brambilla P, Hardan A, di Nemi SU, Perez J, Soares JC, Barale F. Brain anatomy and development in autism: review of structural MRI studies. Brain Res Bull. 2003;61(6):557-69. 
Brothers L. The social brain: a project for integrating primate behaviour and neuropsychology in a new domain. Concepts Neurosci. 1990;1:27-51.

Brunet E, Sarfati Y, Hardy-Bayle MC, Decety J. Abnormalities of brain function during a nonverbal theory of mind task in schizophrenia. Neuropsychologia. 2003;41(12):1574-82.

Brunet-Gouet E, Decety J. Social brain dysfunctions in schizophrenia: a review of neuroimaging studies. Psychiatry Res. 2006;148(2-3):7592.

Cannon TD, Cornblatt B, McGorry P. The empirical status of the ultra high-risk (prodromal) research paradigm. Schizophr Bull. 2007;33(3):661-4.

Cannon TD, Cadenhead K, Cornblatt B, Woods SW, Addington J, Walker E, et al. Prediction of psychosis in youth at high clinical risk: a multisite longitudinal study in North America. Arch Gen Psychiatry. 2008;65(1):28-37.

Capps L, Yirmiya N, Sigman M. Understanding of simple and complex emotions in non-retarded children with autism. J child psychol psychiatry allied discipl. 1992;33(7):1169-82.

Castelli F, Happe F, Frith U, Frith C. Movement and mind: a functional imaging study of perception and interpretation of complex intentional movement patterns. Neuroimage. 2000;12 (3):314-25

Castelli F, Frith C, Happe F, Frith U. Autism, asperger syndrome and brain mechanisms for the attribution of mental states to animated shapes. Brain. 2002;125(Pt 8):1839-49.

Celani G, Battacchi MW, Arcidiacono L. The understanding of the emotional meaning of facial expressions in people with autism. $\mathrm{J}$ Autism Dev Disord. 1999;29(1):57-66.

Chan RC, Di X, McAlonan GM, Gong QY. Brain anatomical abnormalities in high-risk individuals, first-episode, and chronic schizophrenia: an activation likelihood estimation meta-analysis of illness progression. Schizophr Bull. 2009. doi:10.1093/schbul/ $\operatorname{sbp} 073$.

Cheung C, Yu K, Fung G, Leung M, Wong C, Li Q, et al. Autistic disorders and schizophrenia: related or remote? An anatomical likelihood estimation. PLoS ONE. 2010;5(8):e12233.

Convit A, Wolf OT, de Leon MJ, Patalinjug M, Kandil E, Caraos C, et al. Volumetric analysis of the pre-frontal regions: findings in aging and schizophrenia. Psychiatry Res. 2001;107(2):61-73.

Couture SM, Penn DL, Roberts DL. The functional significance of social cognition in schizophrenia: a review. Schizophr Bull. 2006;32 Suppl 1:S44-63.

Couture SM, Penn DL, Losh M, Adolphs R, Hurley R, Piven J. Comparison of social cognitive functioning in schizophrenia and high functioning autism: more convergence than divergence. Psychol Med. 2010;40(4):569-79.

Craig JS, Hatton C, Craig FB, Bentall RP. Persecutory beliefs, attributions and theory of mind: comparison of patients with paranoid delusions, Asperger's syndrome and healthy controls. Schizophr Res. 2004;69(1):29-33.

Crespi B, Badcock C. Psychosis and autism as diametrical disorders of the social brain. Behav Brain Sci. 2008;31(3):241-61. discussion 61-320.

Crespi B, Stead P, Elliot M. Evolution in health and medicine Sackler colloquium: comparative genomics of autism and schizophrenia. Proc Natl Acad Sci USA. 2010;107 Suppl 1:1736-41.

Crespo-Facorro B, Kim J, Andreasen NC, O'Leary DS, Magnotta V. Regional frontal abnormalities in schizophrenia: a quantitative gray matter volume and cortical surface size study. Biol Psychiatry. 2000;48(2):110-9.

Critchley HD, Daly EM, Bullmore ET, Williams SC, Van Amelsvoort $\mathrm{T}$, Robertson DM, et al. The functional neuroanatomy of social behaviour: changes in cerebral blood flow when people with autistic disorder process facial expressions. Brain. 2000;123(Pt 11):2203-12
Dalton KM, Nacewicz BM, Johnstone T, Schaefer HS, Gernsbacher MA, Goldsmith $\mathrm{HH}$, et al. Gaze fixation and the neural circuitry of face processing in autism. Nat Neurosci. 2005;8(4):519-26.

Davatzikos C, Shen D, Gur RC, Wu X, Liu D, Fan Y, et al. Wholebrain morphometric study of schizophrenia revealing a spatially complex set of focal abnormalities. Arch Gen Psychiatry. 2005;62(11):1218-27.

Dawson G, Toth K, Abbott R, Osterling J, Munson J, Estes A, et al. Early social attention impairments in autism: social orienting, joint attention, and attention to distress. Dev Psychol. 2004;40 (2):271-83.

Di Cristo G. Development of cortical GABAergic circuits and its implications for neurodevelopmental disorders. Clin Genet. 2007;72(1):1-8.

Dykens E, Volkmar F, Glick M. Thought disorder in high-functioning autistic adults. J Autism Dev Disord. 1991;21(3):291-301.

Edwards J, Jackson HJ, Pattison PE. Emotion recognition via facial expression and affective prosody in schizophrenia: a methodological review. Clin Psychol Rev. 2002;22(6):789832.

Fatemi SH. Co-occurrence of neurodevelopmental genes in etiopathogenesis of autism and schizophrenia. Schizophr Res. 2010;118 (1-3):303-4.

Fett AK, Viechtbauer W, Dominguez MD, Penn DL, van Os J, Krabbendam L. The relationship between neurocognition and social cognition with functional outcomes in schizophrenia: A meta-analysis. Neurosci Biobehav Rev. 2010. doi:10.1016/j. neubiorev.2010.07.001.

Freeman D. Suspicious minds: the psychology of persecutory delusions. Clin Psychol Rev. 2007;27(4):425-57.

Friedman JM, Baross A, Delaney AD, Ally A, Arbour L, Armstrong $\mathrm{L}$, et al. Oligonucleotide microarray analysis of genomic imbalance in children with mental retardation. Am J Hum Genet. 2006;79(3):500-13

Frith CD. Schizophrenia and theory of mind. Psychol Med. 2004;34 (3):385-9.

Goghari VM, Macdonald AW 3rd, Sponheim SR. Temporal Lobe Structures and Facial Emotion Recognition in Schizophrenia Patients and Nonpsychotic Relatives. Schizophr Bull. 2010. doi:10.1093/schbul/sbq046.

Graham R, Devinsky O, Labar KS. Quantifying deficits in the perception of fear and anger in morphed facial expressions after bilateral amygdala damage. Neuropsychologia. 2007;45(1):4254.

Green WH, Campbell M, Hardesty AS, Grega DM, Padron-Gayol M, Shell J, et al. A comparison of schizophrenic and autistic children. J Am Acad Child Psychiatry. 1984;23(4):399-409.

Green MF, Olivier B, Crawley JN, Penn DL, Silverstein S. Social cognition in schizophrenia: recommendations from the measurement and treatment research to improve cognition in schizophrenia new approaches conference. Schizophr Bull. 2005;31(4):882-7.

Gur RE, Loughead J, Kohler CG, Elliott MA, Lesko K, Ruparel K, et al. Limbic activation associated with misidentification of fearful faces and flat affect in schizophrenia. Arch Gen Psychiatry. 2007;64(12):1356-66.

Hadjikhani N, Joseph RM, Snyder J, Chabris CF, Clark J, Steele S, et al. Activation of the fusiform gyrus when individuals with autism spectrum disorder view faces. Neuroimage. 2004;22(3):1141-50.

Hadjikhani N, Joseph RM, Snyder J, Tager-Flusberg H. Abnormal activation of the social brain during face perception in autism. Hum Brain Mapp. 2007;28(5):441-9.

Hall GB, Doyle KA, Goldberg J, West D, Szatmari P. Amygdala engagement in response to subthreshold presentations of anxious face stimuli in adults with autism spectrum disorders: preliminary insights. PLoS One. 2010;5(5):e10804. 
Happe FG. An advanced test of theory of mind: understanding of story characters' thoughts and feelings by able autistic, mentally handicapped, and normal children and adults. J Autism Dev Disord. 1994;24(2):129-54.

Happe F, Frith U. The weak coherence account: detail-focused cognitive style in autism spectrum disorders. J Autism Dev Disord. 2006;35:5-25.

Harvey PD, Penn D. Social cognition: the key factor predicting social outcome in people with schizophrenia? Psychiatry (Edgmont). 2010;7(2):41-4.

Haut KM, MacDonald 3rd AW. Persecutory delusions and the perception of trustworthiness in unfamiliar faces in schizophrenia. Psychiatry Res. 2010;178(3):456-60.

Haxby JV, Hoffman EA, Gobbini MI. The distributed human neural system for face perception. Trends Cogn Sci. 2000;4(6):223-33.

Hoffman EA, Haxby JV. Distinct representations of eye gaze and identity in the distributed human neural system for face perception. Nat Neurosci. 2000;3(1):80-4.

Holt DJ, Kunkel L, Weiss AP, Goff DC, Wright CI, Shin LM, et al. Increased medial temporal lobe activation during the passive viewing of emotional and neutral facial expressions in schizophrenia. Schizophr Res. 2006;82(2-3):153-62.

Howard MA, Cowell PE, Boucher J, Broks P, Mayes A, Farrant A, et al. Convergent neuroanatomical and behavioural evidence of an amygdala hypothesis of autism. NeuroReport. 2000;11(13):2931-5.

Howlin P. Outcomes in autism spectrum disorders. In: Vokmar FR, Paul R, Klin A, Cohen D, editors. Handbook of autism and pervasive developmental disrders. Hoboken: Wiley; 2005. p. 201-20.

Hrdlicka M, Dudova I, Beranova I, Lisy J, Belsan T, Neuwirth J, et al. Subtypes of autism by cluster analysis based on structural MRI data. Eur Child Adolesc Psychiatry. 2005;14(3):138-44.

Hughes C, Soares-Boucaud I, Hochmann J, Frith U. Social behaviour in pervasive developmental disorders: effects of informant, group and "theory-of-mind". Eur Child Adolesc Psychiatry. 1997;6(4):191-8.

Isohanni M, Jones P, Kemppainen L, Croudace T, Isohanni I, Veijola $\mathrm{J}$, et al. Childhood and adolescent predictors of schizophrenia in the Northern Finland 1966 birth cohort - a descriptive life-span model. Eur Arch Psychiatry Clin Neurosci. 2000;250(6):311-9.

Jones P. The early origins of schizophrenia. Br Med Bull. 1997;53 (1):135-55.

Jones PB, Tarrant CJ. Developmental precursors and biological markers for schizophrenia and affective disorders: specificity and public health implications. Eur Arch Psychiatry Clin Neurosci. 2000;250(6):286-91.

Jou RJ, Minshew NJ, Keshavan MS, Vitale MP, Hardan AY. Enlarged right superior temporal gyrus in children and adolescents with autism. Brain Res. 2010.

Kanner L. Autistic disturbances of affective contact. Nerv Child. 1943;2:217-50.

Kanner L. Problems of nosology and psychodynamics of early infantile autism. Am J Orthopsychiatry. 1949;19(3):416-26.

Kanner L. Infantile autism and the schizophrenias. Behav Sci. 1965;10 (4):412-20.

Kanner L. The birth of early infantile autism. J Autism Child Schizophr. 1973;3(2):93-5.

Kanwisher N, McDermott J, Chun MM. The fusiform face area: a module in human extrastriate cortex specialized for face perception. J Neurosci. 1997;17(11):4302-11.

Keshavan MS, Montrose DM, Pierri JN, Dick EL, Rosenberg D, Talagala L, et al. Magnetic resonance imaging and spectroscopy in offspring at risk for schizophrenia: preliminary studies. Prog neuro psychopharmacol biol psychiatry. 1997;21(8):1285-95.

Keshavan MS, Dick E, Mankowski I, Harenski K, Montrose DM, Diwadkar V, et al. Decreased left amygdala and hippocampal volumes in young offspring at risk for schizophrenia. Schizophr Res. 2002;58(2-3):173-83.
Kim J, Doop ML, Blake R, Park S. Impaired visual recognition of biological motion in schizophrenia. Schizophr Res. 2005;77(2-3):299-307.

Kleinhans NM, Johnson LC, Richards T, Mahurin R, Greenson J, Dawson G, et al. Reduced neural habituation in the amygdala and social impairments in autism spectrum disorders. Am J Psychiatry. 2009;166(4):467-75.

Klin A, Sparrow SS, de Bildt A, Cicchetti DV, Cohen DJ, Volkmar FR. A normed study of face recognition in autism and related disorders. J Autism Dev Disord. 1999;29(6):499-508.

Klin A, Jones W, Schultz R, Volkmar F, Cohen D. Visual fixation patterns during viewing of naturalistic social situations as predictors of social competence in individuals with autism. Arch Gen Psychiatry. 2002;59(9):809-16.

Kohler CG, Walker JB, Martin EA, Healey KM, Moberg PJ. Facial emotion perception in schizophrenia: a meta-analytic review. Schizophr Bull. 2010;36(5):1009-19.

Kolvin I. Studies in the childhood psychoses. I. Diagnostic criteria and classification. Br J Psychiatry. 1971;118(545):381-4.

Kosaka H, Omori M, Murata T, Iidaka T, Yamada H, Okada T, et al. Differential amygdala response during facial recognition in patients with schizophrenia: an fMRI study. Schizophr Res. 2002;57(1):87-95.

Langdell T. Recognition of faces: an approach to the study of autism. $\mathrm{J}$ Child Psychol Psychiatry Allied Discipl. 1978;19(3):255-68.

Langdon R, Ward PB, Coltheart M. Reasoning anomalies associated with delusions in schizophrenia. Schizophr Bull. 2010;36(2):321-30.

Lawrie SM, Whalley HC, Job DE, Johnstone EC. Structural and functional abnormalities of the amygdala in schizophrenia. Ann NY Acad Sci. 2003;985:445-60.

LeDoux JE. The emotional brain. New York: Simon and Schuster; 1996.

Lee CU, Shenton ME, Salisbury DF, Kasai K, Onitsuka T, Dickey CC, et al. Fusiform gyrus volume reduction in first-episode schizophrenia: a magnetic resonance imaging study. Arch Gen Psychiatry. 2002;59 (9):775-81.

Li H, Chan RC, McAlonan GM, Gong QY. Facial emotion processing in schizophrenia: a meta-analysis of functional neuroimaging data. Schizophr Bull. 2010;36(5):1029-39.

Loughland CM, Williams LM, Gordon E. Visual scanpaths to positive and negative facial emotions in an outpatient schizophrenia sample. Schizophr Res. 2002;55(1-2):159-70.

Loveland KA, Tunali-Kotoski B, Chen YR, Ortegon J, Pearson DA, Brelsford KA, et al. Emotion recognition in autism: verbal and nonverbal information. Dev Psychopathol. 1997;9(3):579-93.

Marjoram D, Miller P, McIntosh AM, Cunningham Owens DG, Johnstone EC, Lawrie S. A neuropsychological investigation into 'Theory of Mind' and enhanced risk of schizophrenia. Psychiatry Res. 2006;144(1):29-37.

Marx J. Behavioral genetics. Evidence linking DISC1 gene to mental illness builds. Science. 2007;318(5853):1062-3. New York.

Mier D, Sauer C, Lis S, Esslinger C, Wilhelm J, Gallhofer B, et al. Neuronal correlates of affective theory of mind in schizophrenia out-patients: evidence for a baseline deficit. Psychol Med. 2010;40(10):1607-17.

Mirsky AF, Kugelmass S, Ingraham LJ, Frenkel E, Nathan M. Overview and summary: twenty-five-year followup of high-risk children. Schizophr Bull. 1995;21(2):227-39.

Montag C, Dziobek I, Richter IS, Neuhaus K, Lehmann A, Sylla R, et al. Different aspects of theory of mind in paranoid schizophrenia: evidence from a video-based assessment. Psychiatry Res. 2010. doi:10.1016/j.psychres.2010.09.006.

Mundy P, Sigman M, Ungerer J, Sherman T. Defining the social deficits of autism: the contribution of non-verbal communication measures. J child psychol psychiatry allied discipl. 1986;27 (5):657-69.

Nacewicz BM, Dalton KM, Johnstone T, Long MT, McAuliff EM, Oakes TR, et al. Amygdala volume and nonverbal social 
impairment in adolescent and adult males with autism. Arch Gen Psychiatry. 2006;63(12):1417-28.

Osterling JA, Dawson G, Munson JA. Early recognition of 1-year-old infants with autism spectrum disorder versus mental retardation. Dev Psychopathol. 2002;14(2):239-51.

Palmen SJ, Durston S, Nederveen H, Van Engeland H. No evidence for preferential involvement of medial temporal lobe structures in high-functioning autism. Psychol Med. 2006;36 (6):827-34.

Pelphrey KA, Carter EJ. Charting the typical and atypical development of the social brain. Dev Psychopathol. 2008;20(4):1081-102.

Pelphrey KA, Sasson NJ, Reznick JS, Paul G, Goldman BD, Piven J. Visual scanning of faces in autism. J Autism Dev Disord. 2002;32(4):249-61.

Pelphrey KA, Mitchell TV, McKeown MJ, Goldstein J, Allison T, McCarthy G. Brain activity evoked by the perception of human walking: controlling for meaningful coherent motion. J Neurosci. 2003;23(17):6819-25.

Pelphrey K, Adolphs R, Morris JP. Neuroanatomical substrates of social cognition dysfunction in autism. Ment Retard Dev Disabil Res Rev. 2004a;10(4):259-71.

Pelphrey KA, Viola RJ, McCarthy G. When strangers pass: processing of mutual and averted social gaze in the superior temporal sulcus. Psychol Sci. 2004b;15(9):598-603.

Pelphrey KA, Morris JP, McCarthy G. Neural basis of eye gaze processing deficits in autism. Brain Res. 2005;128(Pt 5):1038-48.

Pelphrey KA, Morris JP, McCarthy G, Labar KS. Perception of dynamic changes in facial affect and identity in autism. Soc Cogn Affect Neurosci. 2007;2(2):140-9.

Penn DL, Corrigan PW, Racenstein JM. Cognitive factors and social adjustment in schizophrenia. In: Mueser K, Tarrier N, editors. Handbook of social functioning in schiziophrenia. Needham Heights: Allyn \& Bacon; 1998. p. 213-23.

Penn D, Addington J, Pinkham AE. Social cognitive impairments. In: Lieberman J, Stroup TS, Perkins DO, editors. The american psychiatric publishing textbook of schizophrenia. Washington, DC: American Psychiatric Publishing; 2006. p. 261-74.

Phillips ML, David AS. Abnormal visual scan paths: a psychophysiological marker of delusions in schizophrenia. Schizophr Res. 1998;29(3):235-45.

Pierce K, Muller RA, Ambrose J, Allen G, Courchesne E. Face processing occurs outside the fusiform 'face area' in autism: evidence from functional MRI. Brain. 2001;124(Pt 10):2059-73.

Pierce K, Haist F, Sedaghat F, Courchesne E. The brain response to personally familiar faces in autism: findings of fusiform activity and beyond. Brain. 2004;127(Pt 12):2703-16.

Pilowsky T, Yirmiya N, Arbelle S, Mozes T. Theory of mind abilities of children with schizophrenia, children with autism, and normally developing children. Schizophr Res. 2000;42(2):145-55.

Pinkham AE, Penn DL. Neurocognitive and social cognitive predictors of interpersonal skill in schizophrenia. Psychiatry Res. 2006;143(2-3):167-78.

Pinkham AE, Penn DL, Perkins DO, Lieberman J. Implications for the neural basis of social cognition for the study of schizophrenia. Am J Psychiatry. 2003;160(5):815-24.

Pinkham AE, Penn DL, Perkins DO, Graham KA, Siegel M. Emotion perception and social skill over the course of psychosis: a comparison of individuals "at-risk" for psychosis and individuals with early and chronic schizophrenia spectrum illness. Cogn Neuropsychiatry. 2007a;12(3):198-212.

Pinkham AE, Gur RE, Gur RC. Affect recognition deficits in schizophrenia: neural substrates and psychopharmacological implications. Expert Rev Neurother. 2007b;7(7):807-16.

Pinkham AE, Hopfinger JB, Pelphrey KA, Piven J, Penn DL. Neural bases for impaired social cognition in schizophrenia and autism spectrum disorders. Schizophr Res. 2008a;99:164-75.
Pinkham AE, Sasson NJ, Calkins ME, Richard J, Hughett P, Gur RE, et al. The other-race effect in face processing among African American and Caucasian individuals with schizophrenia. Am J Psychiatry. 2008b;165(5):639-45.

Quintana J, Wong T, Ortiz-Portillo E, Marder SR, Mazziotta JC. Right lateral fusiform gyrus dysfunction during facial information processing in schizophrenia. Biol Psychiatry. 2003;53 (12):1099-112.

Rasetti R, Mattay VS, Wiedholz LM, Kolachana BS, Hariri AR, Callicott $\mathrm{JH}$, et al. Evidence that altered amygdala activity in schizophrenia is related to clinical state and not genetic risk. Am J Psychiatry. 2009;166(2):216-25.

Rojas DC, Smith JA, Benkers TL, Camou SL, Reite ML, Rogers SJ. Hippocampus and amygdala volumes in parents of children with autistic disorder. Am J Psychiatry. 2004;161(11):2038-44.

Rumsey JM, Rapoport JL, Sceery WR. Autistic children as adults: psychiatric, social, and behavioral outcomes. J Am Acad Child Psychiatry. 1985;24(4):465-73.

Russell TA, Reynaud E, Kucharska-Pietura K, Ecker C, Benson PJ, Zelaya $\mathrm{F}$, et al. Neural responses to dynamic expressions of fear in schizophrenia. Neuropsychologia. 2007;45(1):107-23.

Rutter M. Concepts of autism: a review of research. J Child Psychol Psychiatry. 1968;9(1):1-25.

Rutter M. Childhood schizophrenia reconsidered. J Autism Child Schizophr. 1972;2(4):315-37.

Sasson NJ. The development of face processing in autism. J Autism Dev Disord. 2006;36(3):381-94.

Sasson N, Tsuchiya N, Hurley R, Couture SM, Penn DL, Adolphs R, et al. Orienting to social stimuli differentiates social cognitive impairment in autism and schizophrenia. Neuropsychologia. 2007;45(11):2580-8.

Schopler E, Rutter M, Chess S. Journal of autism and childhood schizophrenia. Change of journal scope and title. J Autism Dev Disord. 1979;9(1):1-10.

Schreiber H, Baur-Seack K, Kornhuber HH, Wallner B, Friedrich JM, De Winter IM, et al. Brain morphology in adolescents at genetic risk for schizophrenia assessed by qualitative and quantitative magnetic resonance imaging. Schizophr Res. 1999;40(1):81-4.

Schultz RT, Gauthier I, Klin A, Fulbright RK, Anderson AW, Volkmar $\mathrm{F}$, et al. Abnormal ventral temporal cortical activity during face discrimination among individuals with autism and asperger syndrome. Arch Gen Psychiatry. 2000;57(4):331-40.

Schumann CM, Hamstra J, Goodlin-Jones BL, Lotspeich LJ, Kwon H, Buonocore $\mathrm{MH}$, et al. The amygdala is enlarged in children but not adolescents with autism; the hippocampus is enlarged at all ages. J Neurosci. 2004;24(28):6392-401.

Seiferth NY, Pauly K, Habel U, Kellermann T, Jon Shah N, Ruhrmann $\mathrm{S}$, et al. Increased neural response related to neutral faces in individuals at risk for psychosis. Neuroimage. 2008;40(1):289-97.

Sheitman BB, Kraus JE, Bodfish JW, Carmel H. Are the negative symptoms of schizophrenia consistent with an autistic spectrum illness? Schizophr Res. 2004;69(1):119-20.

Sparks BF, Friedman SD, Shaw DW, Aylward EH, Echelard D, Artru AA, et al. Brain structural abnormalities in young children with autism spectrum disorder. Neurology. 2002;59(2):184-92.

Sprong M, Schothorst P, Vos E, Hox J, van Engeland H. Theory of mind in schizophrenia: meta-analysis. $\mathrm{Br} \mathrm{J}$ Psychiatry. 2007;191:5-13.

Streit M, Wolwer W, Gaebel W. Facial-affect recognition and visual scanning behaviour in the course of schizophrenia. Schizophr Res. 1997;24(3):311-7.

Szatmari P, Paterson AD, Zwaigenbaum L, Roberts W, Brian J, Liu $\mathrm{XQ}$, et al. Mapping autism risk loci using genetic linkage and chromosomal rearrangements. Nat Genet. 2007;39(3):319-28. 
van Kooten IA, Palmen SJ, von Cappeln P, Steinbusch HW, Korr H, Heinsen $\mathrm{H}$, et al. Neurons in the fusiform gyrus are fewer and smaller in autism. Brain. 2008;131(Pt 4):987-99.

Van Lancker DR, Cornelius C, Kreiman J. Recognition of emotional-prosodic meanings in speech by autistic, schizophrenic, and normal children. Dev Neuropsychol. 1989;5:207-26.

Van't Wout M, van Rijn S, Jellema T, Kahn RS, Aleman A. Deficits in implicit attention to social signals in schizophrenia and high risk groups: behavioural evidence from a new illusion. PLoS ONE. 2009;4(5)):e5581.

Volkmar FR, Cohen DJ. Comorbid association of autism and schizophrenia. Am J Psychiatry. 1991;148(12):1705-7.

Vorstman JA, Morcus ME, Duijff SN, Klaassen PW, Heineman-de Boer JA, Beemer FA, et al. The 22q11.2 deletion in children: high rate of autistic disorders and early onset of psychotic symptoms. J Am Acad Child Adolesc Psychiatry. 2006;45 (9):1104-13.
Walter H, Ciaramidaro A, Adenzato M, Vasic N, Ardito RB, Erk S, et al. Dysfunction of the social brain in schizophrenia is modulated by intention type: an fMRI study. Soc Cogn Affect Neurosci. 2009;4(2):166-76.

Wing L. Clarification on Asperger's syndrome. J Autism Dev Disord. 1986;16(4):513-5.

Winston JS, Henson RN, Fine-Goulden MR, Dolan RJ. fMRI-adaptation reveals dissociable neural representations of identity and expression in face perception. J Neurophysiol. 2004;92(3):1830-9.

Wright IC, Rabe-Hesketh S, Woodruff PW, David AS, Murray RM, Bullmore ET. Meta-analysis of regional brain volumes in schizophrenia. Am J Psychiatry. 2000;157(1):16-25.

Yu Sun C, Kang DH, Na Young S, So Young Y, Jun Soo K. Deficit of theory of mind in individuals at ultra-high-risk for schizophrenia. Schizophr Res. 2008;99(1-3);111-8.

Zwaigenbaum L, Bryson S, Rogers T, Roberts W, Brian J, Szatmari P. Behavioral manifestations of autism in the first year of life. Int $\mathrm{J}$ Dev Neurosci. 2005;23(2-3):143-52. 